\title{
25-OH Vitamin D and Interleukin-8: Emerging Biomarkers in Cutaneous Melanoma Development and Progression
}

\author{
Corina-Daniela Ene, ${ }^{1}$ Amalia-Elena Anghel, ${ }^{2}$ Monica Neagu, ${ }^{3,4}$ and Ilinca Nicolae \\ ${ }^{1}$ Nephrology Hospital "Dr. Carol Davila”, 4 Calea Grivitei, 010731 Bucharest, Romania \\ ${ }^{2}$ SKINMED Clinic, 8 Splaiul Unirii, 040102 Bucharest, Romania \\ ${ }^{3}$ Immunology Department, Victor Babes National Institute of Pathology, 99-101 Splaiul Independentei, 050096 Bucharest, Romania \\ ${ }^{4}$ Faculty of Biology, University of Bucharest, 91-95 Splaiul Independenţei, 76201 Bucharest, Romania \\ ${ }^{5}$ Department in Dermatology, Infectious and Tropical Diseases "Dr. Victor Babeş" Clinical Hospital-Research, \\ 281 Soseaua Mihai Bravu, 030303 Bucharest, Romania \\ Correspondence should be addressed to Monica Neagu; neagu.monica@gmail.com
}

Received 10 April 2015; Revised 5 June 2015; Accepted 10 June 2015

Academic Editor: Madhav Bhatia

Copyright ( 2015 Corina-Daniela Ene et al. This is an open access article distributed under the Creative Commons Attribution License, which permits unrestricted use, distribution, and reproduction in any medium, provided the original work is properly cited.

\begin{abstract}
Background. There are several circulatory biomarkers that are involved in forecasting the clinical outcome of cutaneous melanoma. Serum/plasma vitamin D status is one of the markers intensively studied in this type of cutaneous cancer. The combination of validated serum biomarkers (like LDH) with new biomarkers such as IL-8, angiogenic factor, and vitamin D is still at the dawn of research. Hence, we are aiming to establish the predictive power of inflammatory biomarkers, such as IL-8, and metabolic ones, such as vitamin D. These candidate biomarkers are intended to aid classical biomarkers, such as LDH, in the prognosis of cutaneous melanoma. Methods. Serum vitamin D and IL-8 were quantified in melanoma patients and in matching healthy controls. Results. Median serum vitamin D concentrations were significantly lower $(p=0.003)$ in melanoma patients as compared to healthy control subjects, while around $65 \%$ of the investigated patients have proven a severe circulatory deficiency of this vitamin. IL- 8 was found increased $(p=0.001)$ in melanoma patients as compared to controls. Conclusion. Upregulation of proangiogenic factors associated with vitamin D deficiency can prove to be potent future biomarkers candidates, enhancing the predictive power of classical LDH.
\end{abstract}

\section{Introduction}

A great amount of scientific information has been gathered regarding "vitamin D/cancer hypothesis" [1]. Sun radiation is an environmental factor that can trigger cutaneous melanoma on the one hand, while sun exposure induces skinmediated synthesis of vitamin D3, on the other hand. There are plentiful pro- and retrospective epidemiological studies showing that low serum 25-hydroxyvitamin D3 (25(OH)D) concentrations can be associated with colorectal [2], lung [3], and breast [4] cancer and with various other types of cancer [5]. This association was related with a significantly increased risk for the worst development of the disease and an overall poor prognosis [6]. Besides these studies, there are also several reports showing high serum $25(\mathrm{OH}) \mathrm{D}$ association with lower cancer incidence [7].
Taking into account all the gathered information regarding cutaneous melanoma development, we have embarked in studying the basal serum levels of $25(\mathrm{OH}) \mathrm{D}$ in patients diagnosed with cutaneous melanoma. Knowing that there is no "perfect multipotent biomarker," we have been studying the $25(\mathrm{OH}) \mathrm{D}$ serum level in correlation with classical validated ones, like LDH and newer candidates, like the proangiogenic cytokine IL-8.

Choosing Future Biomarkers. There are several reasons for which we have chosen the presented parameters in melanoma patients and the reasons are highlighted herein.

Interleukin-8 (IL-8), described almost 20 years ago, is a cytokine produced by immune cells (monocytes, macrophages) as well as nonimmune cells (endothelial cells, keratinocytes, melanocytes, and chondrocytes) and tumor cells [8]. 
IL-8 has a strong capacity to specifically activate neutrophils, inducing intracellular calcium rise, reactive oxygen generation, chemotaxis, and enhancement of adhesion molecules expression. Keratinocytes respond to TNF-alpha's action with an IL-8 increased synthesis. IL-8 secretion is correlated with the increased secretion of other chemokines like MCP-1 and IP-10 through NFkappaB activation [9].

IL-8 is produced by several tumor cells and hence its functions include regulation of tumor angiogenesis and immune response. IL-8, along with other chemokines, like CXCL-1 produced by melanoma, has strong influence on primary tumors progression [10] and is able to significantly stimulate Keratin 8 expression in cultured keratinocytes [11].

Overexpression of IL-8 by neoplastic cells seems to be regulated by the hypoxia generated by growing tumors. IL8 overexpression increases CXCR1 and CXCR2 expression on tumor cells, endothelial cells, and immune related cells (neutrophils and macrophages) resident in tumor tissue [12].

Earlier studies have shown that, in melanoma cell lines, 1-alpha, 25-Dihydroxyvitamin D3 (calcitriol) repressed IL-8 promoter activity that was induced by tumor necrosis factoralpha (TNF-alpha). This effect was consistent with the one developed by TNF-alpha upon IL-8 release and upon IL-8 mRNA levels. However, these early studies have shown that only vitamin D3 metabolites, which were able to transactivate a classical vitamin $\mathrm{D}$ response element, had the ability to repress IL-8 promoter activation. This finding suggested that the repression is mediated via vitamin $\mathrm{D}$ receptor (VDR) [13].

Further on, it has been shown that 20-hydroxyvitamin $\mathrm{D}(2)[20(\mathrm{OH}) \mathrm{D}(2)]$ inhibits DNA synthesis in epidermal keratinocytes and in melanoma cells. Transformed melanocytes are more sensitive than normal melanocytes. A noncalcemic analog of vitamin $\mathrm{D}, 20(\mathrm{OH}) \mathrm{D}(2)$, proves cell-type dependent antiproliferative and prodifferentiation activities through activation of VDR, with no detectable toxic calcemic activity [14]. Subsequent studies have shown that indeed melanoma cells express VDR and new insights into the molecular mechanisms that underlie $1,25(\mathrm{OH})(2) \mathrm{D}(3)$-sensitivity in melanoma cells were published. Melanoma cells responsiveness to $1,25(\mathrm{OH})(2) \mathrm{D}(3)$ corresponds to the expression level of VDR mRNA, which in turn might be regulated by VDR microRNAs or epigenetic modulating drugs [15]. Recently, in a large German patients cohort diagnosed with cutaneous melanoma, it was highlighted that a decreased $25(\mathrm{OH}) \mathrm{D}$ level is associated with increased tumor thickness and advanced tumor stage [16].

Lactate-dehydrogenase (LDH) is a validated serum biomarker that evaluates the metastasis risk [17-20] and it actually evaluates the tissue leakage induced by tumor growth and metastasis. An association of the LDH tissue leakage induced by skin damage with an increase of mRNA IL-8 level was reported [21].

In the light of the updated information and in the quest to enhance the panel of biomarkers that could diagnose and prognosticate the cutaneous melanoma outcome, we have investigated the $25-(\mathrm{OH}) \mathrm{D}$ serum concentrations of untreated melanoma patients in correlation with classical serum biomarkers like LDH and possible new biomarkers like IL-8.

\section{Materials and Methods}

2.1. Patients. 88 patients ( 57 women and 31 men) diagnosed with cutaneous melanoma according to AJCC [22] were monitored for 2 years. The presented results were obtained after diagnosis and no installed therapy. Diagnostic was obtained after applying AJCC criteria. The enrolled patients were as follows: Clark II (19.3\%), Clark III (37.5\%), Clark IV (25\%), and Clark V (18.2\%). The prevalence of women versus men was prior highlighted by us [23] where consecutive enrollment of melanoma patients has shown a mean of $75 \%$ women in the entire enrolled group as compared to $80 \%$ women in this study. In EU, this figures show also a prevalence of cutaneous melanoma in women [24].

2.2. Healthy Subjects. Healthy subjects consisted of an equal number of subjects (55 women and 33 men) and are selected from the same geographical regions as the patients (Bucureşti, Argeş, Dîmbovița, Giurgiu, Călăraşi, Constanța, Prahova, Ialomița, and Teleorman).

Patients and healthy subjects have provided their written informed consent. The study and consent procedure were approved by the involved Hospital's Ethics Committee. All the named institutional ethics committees specifically approved this study (ethics committees of Nephrology Hospital "Dr. Carol Davila," Bucharest, Romania; of SKINMED CLINIC, Bucharest, Romania; of "Victor Babes" National Institute of Pathology, of Infectious and Tropical Diseases "Dr. Victor Babeş").

The inclusion and exclusion criteria for the presented study are depicted in Table 1.

2.3. Biological Samples. Blood was harvested from patients and healthy subjects and serum was separated upon standard conditions [25].

Serum Quantification of 25-OH Vitamin D. Quantification was performed with ELISA using Euroimmun kit [26]. The technique has a $1.6 \mathrm{ng} / \mathrm{mL}$ sensitivity for $25-\mathrm{OH}$ vitamins D2 and D3 and no cross-reaction with $24,25(\mathrm{OH})_{2}$ vitamin D3, vitamin D2 (ergocalciferol), and vitamin D3 (cholecalciferol). Briefly, anti-25-OH vitamin D3 antibodies detect the presence of 25-OH vitamin D3 indicated by peroxidase activity, measured as substrate OD at $450 \mathrm{~nm}$. Results are expressed as $\mathrm{ng} / \mathrm{mL}$ or $\mathrm{nmol} / \mathrm{L}$, after the following formula: $25-\mathrm{OH}$ vitamin D3 $(n g / m L) \times 2.5=25-O H$ vitamin D3 $(\mathrm{nmol} / \mathrm{L})$.

2.4. Serum Quantification of $I L-8$. Quantification was performed with ELISA using Enzo Life Sciences kit, with a detection limit of $0.64 \mathrm{pg} / \mathrm{mL}$ [27].

2.5. Serum Lactate-Dehydrogenase. (LDH) was quantified using standard photometric method (Human Diagnostics) and the results were expressed in $\mathrm{UL}^{-1}$.

2.6. Standard Laboratory Evaluation. Hematology and general biochemistry were evaluated in an Automated Biochemical Analyzer. 
TABLE 1: Inclusion and exclusion criteria for patients (a) and healthy subjects (b).

(a) Patients

\begin{tabular}{|c|c|c|}
\hline \multirow{4}{*}{ Inclusion criteria } & Age & $18-45$ years \\
\hline & Sun exposure & UV index 5 \\
\hline & Nutrition, body mass index & Normal, 18.5-24.9 \\
\hline & Stage & Clark II, Clark III, Clark IV, and Clark V \\
\hline \multirow{5}{*}{ Exclusion criteria } & Age & $>18$ years; $<45$ years \\
\hline & Pregnancy & Yes \\
\hline & Condition present & Drug and/or alcoholic addiction \\
\hline & Treatment present & $\begin{array}{l}\text { Systemic treatment with hormones, antidepressants, antioxidants, } \\
\text { and immunomodulators }\end{array}$ \\
\hline & Other pathologies & $\begin{array}{l}\text { Neurological, physiatrical, digestive, endocrinological, and } \\
\text { cardiovascular diseases, liver-, renal-, and lung-related pathologies, } \\
\text { metabolic disease, autoimmune, infections, inflammations, and other } \\
\text { neoplastic diseases }\end{array}$ \\
\hline
\end{tabular}

(b) Healthy subjects

\begin{tabular}{|c|c|c|}
\hline \multirow{4}{*}{ Inclusion criteria } & Age & $18-45$ years \\
\hline & Sun exposure & UV index 5 \\
\hline & Nutrition, body mass index & Normal, 18.5-24.9 \\
\hline & $\begin{array}{l}\text { Calcemia, calciuria, phosphatemia, } \\
\text { alkaline phosphatase, } \\
\text { parathormone, and C reactive } \\
\text { protein. }\end{array}$ & Normal values \\
\hline \multirow{5}{*}{ Exclusion criteria } & Age & $>18$ years; $<45$ years \\
\hline & Pregnancy & Yes \\
\hline & Condition present & Drug and/or alcoholic addiction \\
\hline & Treatment present & $\begin{array}{l}\text { Systemic treatment with hormones, antidepressants, antioxidants, } \\
\text { and immunomodulators }\end{array}$ \\
\hline & Other pathologies & $\begin{array}{l}\text { Neurological, physiatrical, digestive, endocrinological, and } \\
\text { cardiovascular diseases, liver-, renal-, and lung-related pathologies, } \\
\text { metabolic disease, autoimmune, infections, inflammations, and other } \\
\text { neoplastic diseases }\end{array}$ \\
\hline
\end{tabular}

2.7. Statistics. SPSS program was used for data analysis; comparison was performed using Student's $t$-test for $p<0.05$. For several comparisons, the ANOVA multiparametric test was used. The correlation was established using linear regression and Pearson correlation. The results are presented as mean with standard deviation and as prevalence, the proportion of normal subjects/patients with a specific parameter.

\section{Results}

Overall biochemical parameters of the investigated patients are presented in Table 2 . As seen, there were no statistically significant differences between lipids, triglyceride, bilirubin, calcemia, phosphatemia, alkaline phosphatase, iPTH, CRP, and calciuria in patients compared to controls.

While standard biochemical parameters are not changed in the melanoma group, serum LDH, IL-8 and vitamin D3 are statistically significantly different (Figures 1 and 2).
Control IL-8 serum values match our previously published report [23], while patient values are elevated in comparison to our previous report. These differences reside first in the different patients' group population and secondly in the different used methods, ELISA versus multiplex technology. Patients' values for serum IL- 8 are matching the overall range previously published when using ELISA as detection method [28].

Serum LDH is statistically increased in patients group compared to controls. The general accepted reference level for serum $\mathrm{LDH}$ is in the range of $135-450 \mathrm{UL}^{-1}$. In $63.63 \%$ from the investigated cases, the registered value was in the reference level, while in the other $36.37 \%$ cases it was higher than the reference levels. For controls, $97.73 \%$ proved serum $\mathrm{LDH}$ values in the reference domain.

Regarding serum IL-8 concentration, $84.1 \%$ from the investigated cases had high values, while only $15.9 \%$ had values in the reference domain. In controls, $99 \%$ of the donors had lower than $15.0 \mathrm{pg} \mathrm{mL}^{-1}$ serum concentration of IL-8. 
TABLE 2: Biochemical parameters.

\begin{tabular}{|c|c|c|c|}
\hline Parameter & Patients & Control & $\begin{array}{c}p \text { significance } \\
\text { (patients versus control) }\end{array}$ \\
\hline Lipids $\left(\mathrm{g} \mathrm{dL}^{-1}\right)$ & $618.7 \pm 26.4$ & $601.0 \pm 37.1$ & 0.741 \\
\hline Triglycerides $\left(\mathrm{mg} \mathrm{dL}^{-1}\right)$ & $89.9 \pm 18.6$ & $83.4 \pm 16.6$ & 0.449 \\
\hline Bilirubin $\left(\mathrm{mg} \mathrm{dL}^{-1}\right)$ & $0.22 \pm 0.03$ & $0.19 \pm 0.08$ & 0.811 \\
\hline Calcemia $\left(\mathrm{mg} \mathrm{dL}^{-1}\right)$ & $8.87 \pm 0.30$ & $8.76 \pm 0.24$ & 0.902 \\
\hline Calciuria (mg/24 h) & $162.6 \pm 31.4$ & $153.9 \pm 20.7$ & 0.381 \\
\hline Alkaline phosphatase $\left(\mathrm{UL}^{-1}\right)$ & $216.4 \pm 31.5$ & $209.7 \pm 23.1$ & 0.428 \\
\hline iPTH $\left(\mathrm{pg} \mathrm{mL}^{-1}\right)$ & $27.2 \pm 7.4$ & $31.0 \pm 8.7$ & 0.517 \\
\hline Phosphatemia (mg dL ${ }^{-1}$ ) & $3.6 \pm 0.9$ & $3.4 \pm 0.6$ & 0.726 \\
\hline $\mathrm{CRP}\left(\mathrm{mg} \mathrm{dL}^{-1}\right)$ & $0.39 \pm 0.23$ & $0.13 \pm 0.15$ & 0.121 \\
\hline $\mathrm{LDH}\left(\mathrm{UL}^{-1}\right)$ & $396 \pm 79$ & $203 \pm 62$ & 0.014 \\
\hline IL-8 $\left(p g \mathrm{~mL}^{-1}\right)$ & $68.1 \pm 16.3$ & $10.2 \pm 4.5$ & 0.001 \\
\hline $25(\mathrm{OH}) \mathrm{D}\left(\mathrm{ng} \mathrm{mL}^{-1}\right)$ & $15.9 \pm 11.8$ & $26.8 \pm 14.4$ & 0.003 \\
\hline
\end{tabular}

CRP: C reactive protein; iPTH: intact parathormone; LDH: lactate-dehydrogenase; IL-8: interleukin-8; and 25(OH)D3: 25-hydroxyvitamin D3.

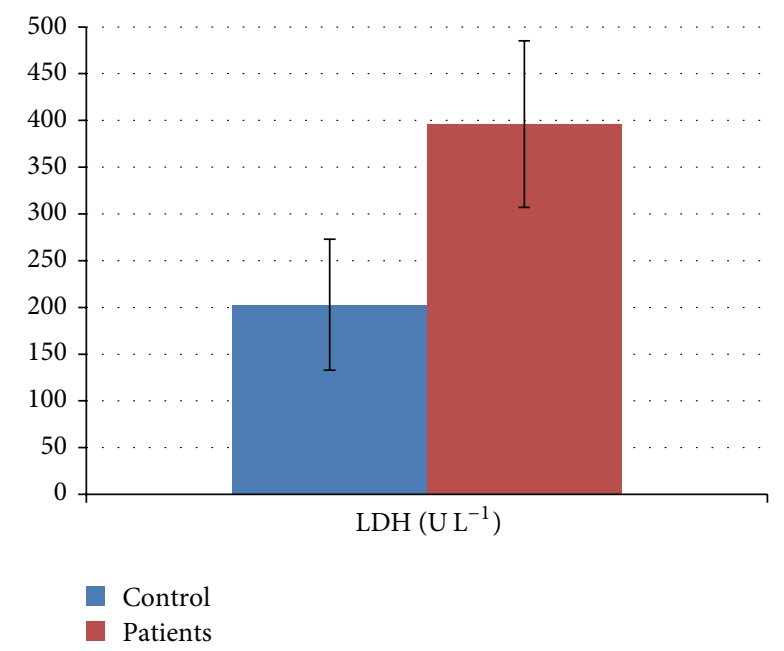

Figure 1: Serum LDH $\left(\mathrm{UL}^{-1}\right)$ in cutaneous melanoma patients compared to healthy controls. Statistically significant differences were registered for serum LDH $(p=0.014)$.

The serum level for 25-OH vitamin D3 is highly influenced by age, sex, diet, geographical location of the individual, sun exposure, and so on. There is still no consensus regarding the so-called normal value range for serum $25-\mathrm{OH}$ vitamin D3. We have chosen healthy individuals from various geographical regions in Romania, both southern regions and lower mountain regions. Healthy donors were chosen to match the same geo/demographical and dietary lifestyle as the patients. Hence, the normal values that we present herein are the optimum normal values for the investigated patients group in the 18-45 years of age range, without claiming that it is the optimal range for the overall Romanian population.

As seen in Figure 2 and Table 3, patients have a clear vitamin D3 deficiency in comparison to controls, a mean of almost 50\% reduction compared to healthy individuals. More

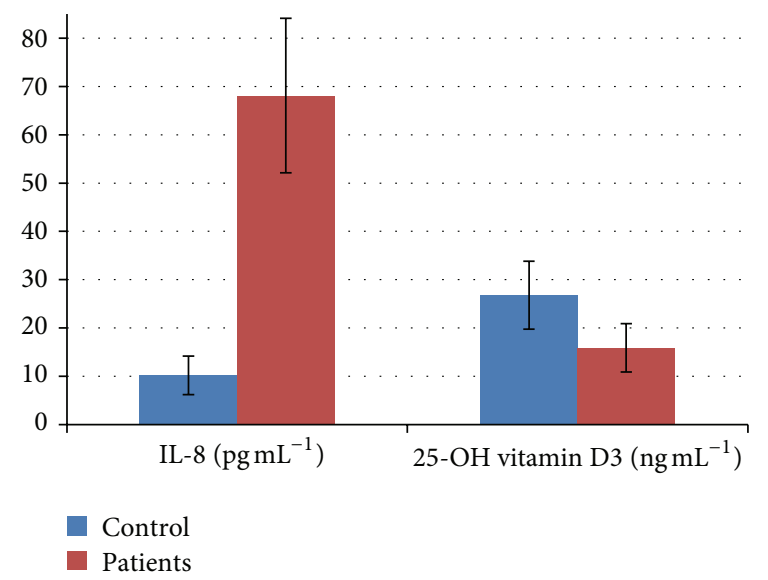

FIgURE 2: Serum IL-8 (pg mL $\left.{ }^{-1}\right)$ and 25-OH vitamin D3 (ng mL $\left.{ }^{-1}\right)$ in cutaneous melanoma patients compared to healthy controls. Statistically significant differences were registered for serum IL-8 $(p=0.001)$ and for $25-\mathrm{OH}$ vitamin D3 $(p=0.003)$.

than $50 \%$ of the normal donors have low levels of $25-\mathrm{OH}$ vitamin D3 (less than $30 \mathrm{ng} \mathrm{mL}^{-1}$, Table 3).

From the data gathered and presented in Table 3 we have generated Figures 3, 4, and 5 depicting the subgroups displaying low, medium, normal, and high concentration of serum vitamin D3. Vitamin D3 deficiency has a higher prevalence in melanoma patients; only $8.0 \%$ display an optimum level (range $30-50 \mathrm{ng} \mathrm{mL}^{-1}$ ), while $92.0 \%$ have low serum levels (Figure 3 ).

The identified deficiency is correlated with modifications of both serums LDH and IL-8 in melanoma patients. Therefore, there is a negative correlation between serum $25-\mathrm{OH}$ vitamin D3 and IL-8 $(r=-0.650, p=0.005)$ and $\mathrm{LDH}$ $(r=-0.426, p=0.021)$. In controls, no correlations between these parameters were identified. Clinically, serum $25-\mathrm{OH}$ 
TABLE 3: Serum 25-OH vitamin D3 concentration in patients and healthy donors.

\begin{tabular}{lccc}
\hline Vitamin D3 & 25-OH vitamin D3 $\left(\mathrm{ng} \mathrm{mL} \mathrm{mL}^{-1}\right)$ & Patients (number) & Control (number) \\
\hline Very severe deficiency & $1.6-5$ & 2 & 0 \\
Severe deficiency & $5-10$ & 4 & 2 \\
Deficiency & $10-20$ & 24 & 9 \\
Suboptimal provision & $20-30$ & 7 & 36 \\
Optimal level & $30-50$ & 0 & 38 \\
Upper level & $50-70$ & 0 & 3 \\
Overdose, but not toxic & $70-150$ & 0 & 0 \\
Intoxication & $>150$ & 0 & 0 \\
\hline
\end{tabular}

TABLE 4: Statistical correlations between serum 25-OH vitamin D3, IL-8, and LDH in patients group and controls.

\begin{tabular}{lccr}
\hline $\begin{array}{l}\text { Investigated serum parameters } \\
\text { (correlated pair of variables) }\end{array}$ & \multicolumn{2}{c}{ Cutaneous melanoma } & \multicolumn{2}{c}{ Controls } & \multicolumn{1}{c}{$p$} \\
\hline 25-OH vitamin D3 versus IL-8 & -0.650 & 0.005 & -0.143 \\
25-OH vitamin D3 versus LDH & -0.426 & 0.021 & 0.062 \\
IL-8 versus LDH & 0.311 & 0.006 & 0.028 \\
\hline
\end{tabular}

$r$ : correlation coefficient; $p$ : statistical significance.

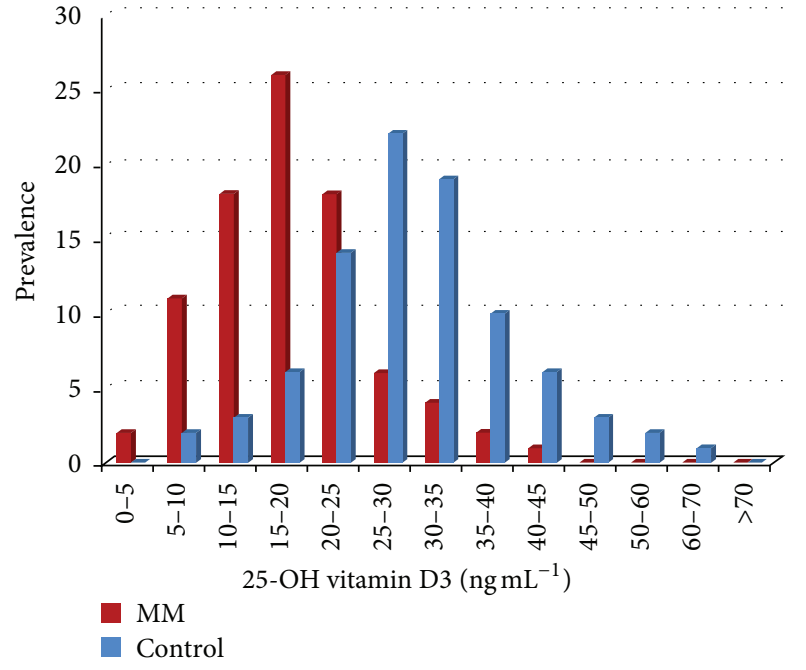

Figure 3: 25-OH vitamin D3 serum level $\left(\mathrm{ng} \mathrm{mL}^{-1}\right)$ in melanoma patients (MM) compared to controls. Prevalence depicts the subgroups of low serum 25-OH vitamin D3 in the melanoma group of patients.

vitamin D3 deficit associated with high serum LDH and IL8 indicated a metastatic risk for the investigated patients (Figures 4 and 5).

When evaluating the statistics and using linear regression, we have obtained a clear positive correlation between serum LDH (the only validated serum biomarker in cutaneous melanoma) and the circulatory levels of IL-8, a protumoral and proangiogenic factor (Table 4). Negative correlation was obtained between serum vitamin D3 and IL-8 and/or LDH (Table 4).

As studies over biomarkers discovery abound in melanoma, there is a continuous need of new serum biomarkers

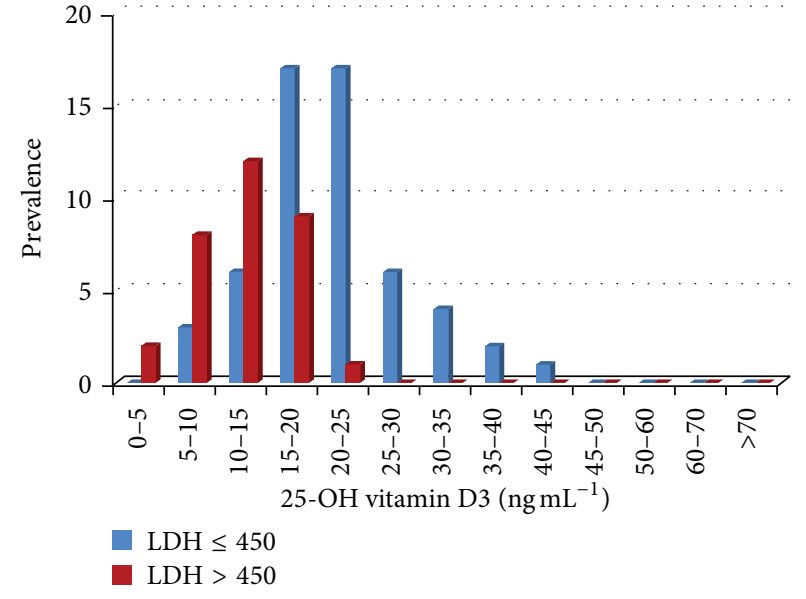

FIGURE 4: 25-OH vitamin D3 (ng $\left.\mathrm{mL}^{-1}\right)$ serum level in melanoma patients for individuals with normal and high LDH serum levels $\left(\mathrm{UL}^{-1}\right)$. Prevalence depicts the subgroups of melanoma patients with high serum LDH congregating in the low serum $25-\mathrm{OH}$ vitamin D3 ranges.

pin-pointing melanoma progression [29]. Our study stresses the fact that LDH, as a single approved marker, cannot spot the complex disease's evolution. Combining this classical biomarker with vitamin D3 and IL-8 can increase the predictive power of biomarkers and provide efficient rationale for follow-up and various treatment choices.

\section{Discussion}

The search for new prediction biomarkers in cutaneous melanoma, early detection, and prognosticators is still an unmet need. We have shown herein that melanoma progression is associated with a decrease in the serum level of 


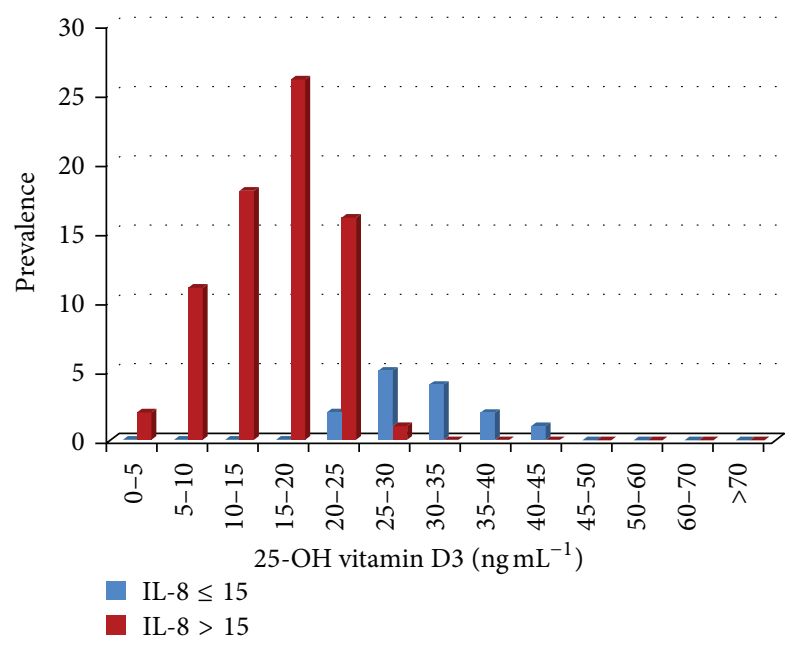

FIgURe 5: 25-OH vitamin D3 (ng mL $\mathrm{m}^{-1}$ ) serum level in melanoma patients for individuals with normal and high serum IL-8 $\left(\mathrm{pg} \mathrm{mL}^{-1}\right)$. Prevalence depicts the subgroups of melanoma patients with high serum IL-8 congregating in the low serum $25-\mathrm{OH}$ vitamin D3 ranges.

25-OH vitamin D3. There is a clear deficit of this vitamin in patients compared to controls, and this deficiency is negatively correlated with conventional biomarkers, such as LDH. When transition from the horizontal to vertical growth starts in cutaneous melanoma, and the metastatic process initiation is triggered, there is a drastic decrease of serum 25-OH vitamin D3, while LDH (tissue destruction) and IL8 (angiogenesis) increase.

A decrease of 25-OH vitamin D3 serum level represents a bad clinical outcome of melanoma. These results join the confirmation studies that are conveyed towards vitamin D3 involvement in tumorigenesis, invasion, and metastasis.

There are still contradictions related to vitamin D3 and melanoma development. While several studies have shown positive association between dietary vitamin D3 intake and melanoma incidence [30], others have flagged a negative correlation [7] or the lack of any correlation [31].

Knowing that UV radiation is an environmental risk factor for cutaneous melanoma, but a trigger for vitamin D synthesis, we have enrolled patients and controls from geographical regions with higher and lower sun radiance, keeping the same UV index. In terms of environmental exposure, we did not find any correlation between the geographical region and vitamin D serum level.

The circulatory levels of vitamin D that we report in controls match the previously reported range in German population. The vitamin $\mathrm{D}$ data for patients presented herein are below the ones published for the German melanoma patients. In the German population, previous reports showed that the decreased vitamin D serum levels were associated with increased tumor thickness and advanced tumor stage [16]. In recent research studies, IL-8, an intense studied proangiogenic factor, was reported as one of the cytokines secreted by melanoma cells, influencing thus the differentiation pattern of keratinocytes and being a factor that mediates intercellular interactions in melanoma [32]. Moreover, it was shown that elevated IL-8 secretion and change in CXCR expression enhance melanoma malignancy [33]. Results performed in several solid cancers showed that serum IL-8 indicates tumor burden and prognosis in melanoma as well [34]. In our study, besides the correlation with the presence of melanoma tumor, the elevated serum IL-8 statistically correlated with an enhanced LDH and a reduced circulatory vitamin D.

We can speculate an intricate regulatory mechanism portrayed by these biomarkers. Thus, knowing that vitamin $\mathrm{D}$ metabolites have a repressive effect on IL- 8 promoter activation [13] we can ascertain that low levels of vitamin D can turn off vitamin D receptor (VDR) stimulation, lowering IL-8 gene repression and hence an increase of proinflammatory IL-8 expression. Inflammatory milieu as proven in many types of cancer (here represented by IL-8) go hand in hand with an active tumor cell metabolism, represented by high levels of $\mathrm{LDH}$ [35]. Other inflammatory markers, as CRP and galectin3 , were prior correlated in melanoma with an increase in LDH [36] and circulatory markers such as S100 and MIA [37]. Recently it was demonstrated in normal melanocytes that triggering the apoptosis and hence the $\mathrm{LDH}$ release, genes encoding for proinflammatory cytokines like IL-8, are activated as well [38].

In the light of the presented results, we can draw a preliminary biomarker pattern for enhanced risk of developing the metastasis stage in melanoma for patients that have vitamin D deficiency, doubled by an increased circulatory IL-8 and $\mathrm{LDH}$.

\section{Conclusions}

The direct relation between sun exposure and melanocyte malignant transformation is complex. Upon sun exposure, melanoma risks increases, especially in the case of sunburn, when inflammation occurs [39]. If vitamin D3 levels are decreased, unbalanced metabolic disorder can lead to further uncontrolled tumorigenesis. On national level, there is no large cohort screening for vitamin D3 level; thus we were confronted with the lack of information regarding the normal values and the population deficit.

Therapeutically, using vitamin D3 or its analogs can induce toxic effects (immune-suppression, hypercalcemia, multiple organ insufficiency, and death), but the recently developed new analogs have less toxicity and proved antitumoral effects in in vitro studies [40]. Low levels of circulatory vitamin D3 are much more frequent in melanoma patients compared to controls (92\% versus 53\%); these levels could indicate a high risk patient subpopulation and, using the new possibilities to therapeutically correct this deficiency, assist melanoma patients management.

Although imaging new technologies is evolving in dermatooncology [41], finding new biomarkers and/or enlarging the biomarkers panel for monitoring melanoma patients with parameters as vitamin $\mathrm{D}$ and IL- 8 could both aid the prognosis of the disease and could identify high risk subgroups. 


\section{Ethical Approval}

The authors state that they have obtained appropriate institutional review board approval and have followed the principles outlined in the Declaration of Helsinki for all human experimental investigations. In addition, for all our investigations, informed consent has been obtained from the participants involved.

\section{Conflict of Interests}

The authors declare that there is no conflict of interests regarding the publication of this paper.

\section{Acknowledgment}

Authors Amalia-Elena Anghel and Corina-Daniela Ene received financial support through the "CERO-CAREER Profile: ROMANIAN Researchers", Contract no. HRD/159/ 1.5/S/135760 financed from the European Social Fund through Sectorial Operational Programme Human Resources Development 2007-2013. Monica Neagu received funding support through UEFISCDI research project PN-II-PCCA2013-4-1407 (acronym MELTAG, Grant no. 190/2014).

\section{References}

[1] B. Vandewalle, A. Adenis, L. Hornez, F. Revillion, and J. Lefebvre, "1,25-dihydroxyvitamin D3 receptors in normal and malignant human colorectal tissues," Cancer Letters, vol. 86, no. 1, pp. 67-73, 1994.

[2] M. Song, R. Nishihara, M. Wang et al., "Plasma 25-hydroxyvitamin D and colorectal cancer risk according to tumour immunity status," Gut, 2015.

[3] K. Sharma, R. W. Goehe, X. Di et al., "A novel cytostatic form of autophagy in sensitization of non-small cell lung cancer cells to radiation by vitamin D and the vitamin D analog, EB 1089," Autophagy, vol. 10, no. 12, pp. 2346-2361, 2015.

[4] S. Imtiaz and N. Siddiqui, "Vitamin-D status at breast cancer diagnosis: correlation with social and environmental factors and dietary intake," Journal of Ayub Medical College Abbottabad, vol. 26, no. 2, pp. 186-190, 2014.

[5] A. Juzeniene, A. C. Porojnicu, Z. Baturaite et al., "Vitamin D levels and dietary intake among patients with benign soft tissue tumors and sarcomas," Anticancer Research, vol. 35, no. 2, pp. 1171-1180, 2015.

[6] K. M. Wesa, N. H. Segal, A. M. Cronin et al., "Serum 25hydroxy vitamin $\mathrm{D}$ and survival in advanced colorectal cancer: a retrospective analysis," Nutrition and Cancer, vol. 67, no. 3, pp. 424-430, 2015.

[7] B. Bade, A. Zdebik, S. Wagenpfeil et al., "Low serum 25hydroxyvitamin D concentrations are associated with increased risk for melanoma and unfavourable prognosis," PLOS ONE, vol. 9, no. 12, Article ID el12863, 2014.

[8] H. B. Lowman, W. J. Fairbrother, P. H. Slagle et al., "Monomeric variants of IL-8: effects of sidechain substitutions and solution conditions upon dimer formation," Protein Science, vol. 6, no. 3, pp. 598-608, 1997.

[9] S. Pastore, D. Lulli, A. I. Potapovich et al., "Differential modulation of stress-inflammation responses by plant polyphenols in cultured normal human keratinocytes and immortalized HaCaT cells," Journal of Dermatological Science, vol. 63, no. 2, pp. 104-114, 2011.

[10] C. R. Mangahas, G. V. dela Cruz, G. Friedman-Jiménez, and S. Jamal, "Endothelin-1 induces CXCL1 and CXCL8 secretion in human melanoma cells," Journal of Investigative Dermatology, vol. 125, no. 2, pp. 307-311, 2005.

[11] M. Kolář, P. Szabo, B. Dvořánková et al., "Upregulation of IL6, IL-8 and CXCL-1 production in dermal fibroblasts by nor$\mathrm{mal} /$ malignant epithelial cells in vitro: immunohistochemical and transcriptomic analyses," Biology of the Cell, vol. 104, no. 12, pp. 738-751, 2012.

[12] D. J. J. Waugh and C. Wilson, "The interleukin-8 pathway in cancer," Clinical Cancer Research, vol. 14, no. 21, pp. 6735-6741, 2008.

[13] H. Harant, P. J. Andrew, G. S. Reddy, E. Foglar, and I. J. D. Lindley, " $1 \alpha, 25$-dihydroxyvitamin $\mathrm{D}_{3}$ and a variety of its natural metabolites transcriptionally repress nuclear-factor- $\kappa \mathrm{B}$ mediated interleukin-8 gene expression," European Journal of Biochemistry, vol. 250, no. 1, pp. 63-71, 1997.

[14] A. T. Slominski, T.-K. Kim, Z. Janjetovic et al., "20-Hydroxyvitamin D2 is a noncalcemic analog of vitamin $\mathrm{D}$ with potent antiproliferative and prodifferentiation activities in normal and malignant cells," The American Journal of Physiology-Cell Physiology, vol. 300, no. 3, pp. C526-C541, 2011.

[15] S. Essa, S. Reichrath, U. Mahlknecht, M. Montenarh, T. Vogt, and J. Reichrath, "Signature of VDR miRNAs and epigenetic modulation of vitamin D signaling in melanoma cell lines," Anticancer Research, vol. 32, no. 1, pp. 383-389, 2012.

[16] T. Gambichler, M. Bindsteiner, S. Höxtermann, and A. Kreuter, "Serum 25-hydroxyvitamin D serum levels in a large German cohort of patients with melanoma," British Journal of Dermatology, vol. 168, no. 3, pp. 625-628, 2013.

[17] S. Kelderman, B. Heemskerk, H. van Tinteren et al., "Lactate dehydrogenase as a selection criterion for ipilimumab treatment in metastatic melanoma," Cancer Immunology, Immunotherapy, vol. 63, no. 5, pp. 449-458, 2014.

[18] S. R. Palmer, L. A. Erickson, I. Ichetovkin, D. J. Knauer, and S. N. Markovic, "Circulating serologic and molecular biomarkers in malignant melanoma," Mayo Clinic Proceedings, vol. 86, no. 10, pp. 981-990, 2011.

[19] C. D. Nicolae and I. Nicolae, "Antibodies against GM1 Gangliosides associated with metastatic melanoma," Acta Dermatovenerologica Croatica, vol. 21, no. 2, pp. 86-92, 2013.

[20] C. D. Ene and I. Nicolae, "Gangliosides and antigangliosides in malignant melanoma," in Melanoma-Current Clinical Management and Future Therapeutics, M. Murph, Ed., chapter 14, InTech, Rijeka, Croatia, 2015.

[21] H. Zhai and H. I. Maibach, Eds., Dermatotoxicology, CRC Press, 6th edition, 2004.

[22] "Melanoma of the skin," in AJCC Cancer Staging Manual, S. B. Edge, D. R. Byrd, C. C. Compton et al., Eds., pp. 325-344, Springer, New York, NY, USA, 7th edition, 2010.

[23] M. Neagu, C. Constantin, and S. Zurac, "Immune parameters in the prognosis and therapy monitoring of cutaneous melanoma patients: experience, role, and limitations," BioMed Research International, vol. 2013, Article ID 107940, 13 pages, 2013.

[24] J. Ferlay, E. Steliarova-Foucher, J. Lortet-Tieulent et al., "Cancer incidence and mortality patterns in Europe: estimates for 40 countries in 2012," European Journal of Cancer, vol. 49, no. 6, pp. 1374-1403, 2013. 
[25] P. W. Thavasu, S. Longhurst, S. P. Joel, M. L. Slevin, and F. R. Balkwill, "Measuring cytokine levels in blood. Importance of anticoagulants, processing, and storage conditions," Journal of Immunological Methods, vol. 153, no. 1-2, pp. 115-124, 1992.

[26] http://www.euroimmun.ch/uploads/media/EQ_6411_I_UK_A02 .pdf.

[27] http://www.enzolifesciences.com/ADI-900-156/il-8-humanelisa-kit/.

[28] H. Zhang, T. Fu, S. McGettigan et al., "IL-8 and cathepsin $\mathrm{B}$ as melanoma serum biomarkers," International Journal of Molecular Sciences, vol. 12, no. 3, pp. 1505-1518, 2011.

[29] P. Vereecken, F. Cornelis, N. Van Baren, V. Vandersleyen, and J.-F. Baurain, "A synopsis of serum biomarkers in cutaneous melanoma patients," Dermatology Research and Practice, vol. 2012, Article ID 260643, 7 pages, 2012.

[30] M. Vinceti, C. Malagoli, C. Fiorentini et al., "Inverse association between dietary vitamin $\mathrm{D}$ and risk of cutaneous melanoma in a Northern Italy population," Nutrition and Cancer, vol. 63, no. 4, pp. 506-513, 2011.

[31] U. Reinhold, B. Schmitz, C. Kurbacher, W. Nagel, M. Schmidt, and W. J. Malaisse, "Circulating 25-hydroxyvitamin D concentration in German cancer patients," Oncology Reports, vol. 20, no. 6, pp. 1539-1543, 2008.

[32] O. Kodet, L. Lacina, E. Krejčí et al., "Melanoma cells influence the differentiation pattern of human epidermal keratinocytes," Molecular Cancer, vol. 14, no. 1, article 1, 2015.

[33] W. Uen, C. Hsieh, T. Tseng, S. S. Jiang, J. Tseng, and S. Lee, "Anchorage independency promoted tumor malignancy of melanoma cells under reattachment through elevated interleukin-8 and CXC chemokine receptor 1 expression," Melanoma Research, vol. 25, no. 1, pp. 35-46, 2015.

[34] M. F. Sanmamed, O. Carranza-Rua, C. Alfaro et al., "Serum interleukin- 8 reflects tumor burden and treatment response across malignancies of multiple tissue origins," Clinical Cancer Research, vol. 20, no. 22, pp. 5697-5707, 2014.

[35] M. A. Khan, S. Andrews, R. Ismail-Khan et al., "Overall and progression-free survival in metastatic melanoma: analysis of a single-institution database," Cancer Control, vol. 13, no. 3, pp. 211-217, 2006.

[36] P. Vereecken, K. Z. Boudjeltia, C. Debray et al., "High serum galectin-3 in advanced melanoma: preliminary results," Clinical and Experimental Dermatology, vol. 31, no. 1, pp. 105-109, 2006.

[37] M. Neagu, C. Constantin, G. Manda, and I. Margaritescu, "Biomarkers of metastatic melanoma," Biomarkers in Medicine, vol. 3, no. 1, pp. 71-89, 2009.

[38] S. Wang, D. Liu, W. Ning, and A. Xu, "Cytosolic dsDNA triggers apoptosis and pro-inflammatory cytokine production in normal human melanocytes," Experimental Dermatology, vol. 24, no. 4, pp. 298-300, 2015.

[39] M. Neagu, C. Constantin, G. R. Dumitrascu et al., "Inflammation markers in cutaneous melanoma-edgy biomarkers for prognosis," Discoveries, vol. 3, no. 1, Article ID e38114, 2015.

[40] J. Chen, J. Wang, T. K. Kim et al., "Novel vitamin D analogs as potential therapeutics: metabolism, toxicity profiling, and antiproliferative activity," Anticancer Research, vol. 34, no. 5, pp. 2153-2163, 2014.

[41] A. Diaconeasa, D. Boda, M. Neagu et al., "The role of confocal microscopy in the dermato-oncology practice," Journal of Medicine and Life, vol. 4, no. 1, pp. 63-74, 2011. 


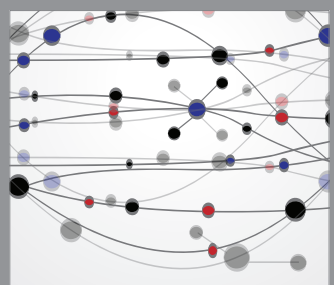

The Scientific World Journal
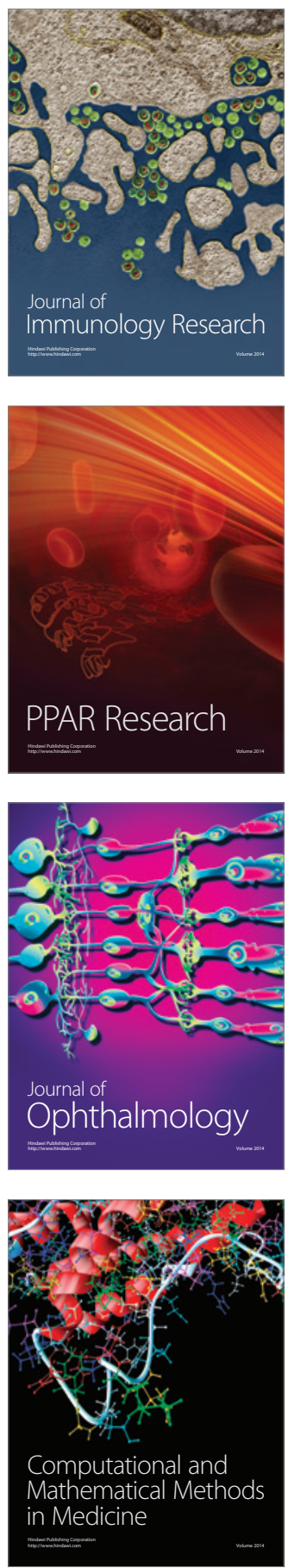

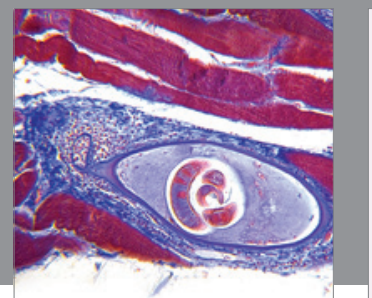

Gastroenterology

Research and Practice
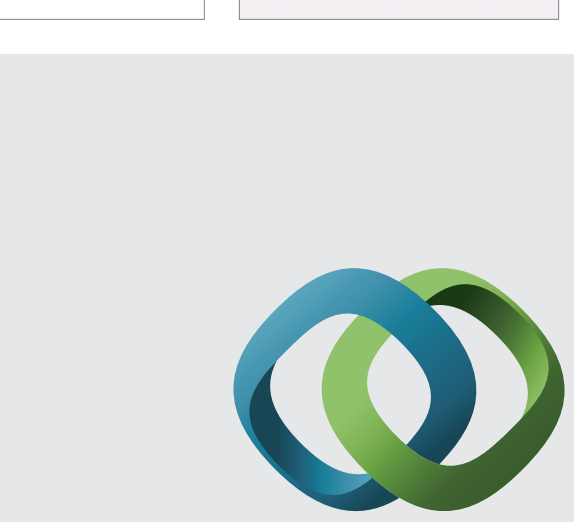

\section{Hindawi}

Submit your manuscripts at

http://www.hindawi.com
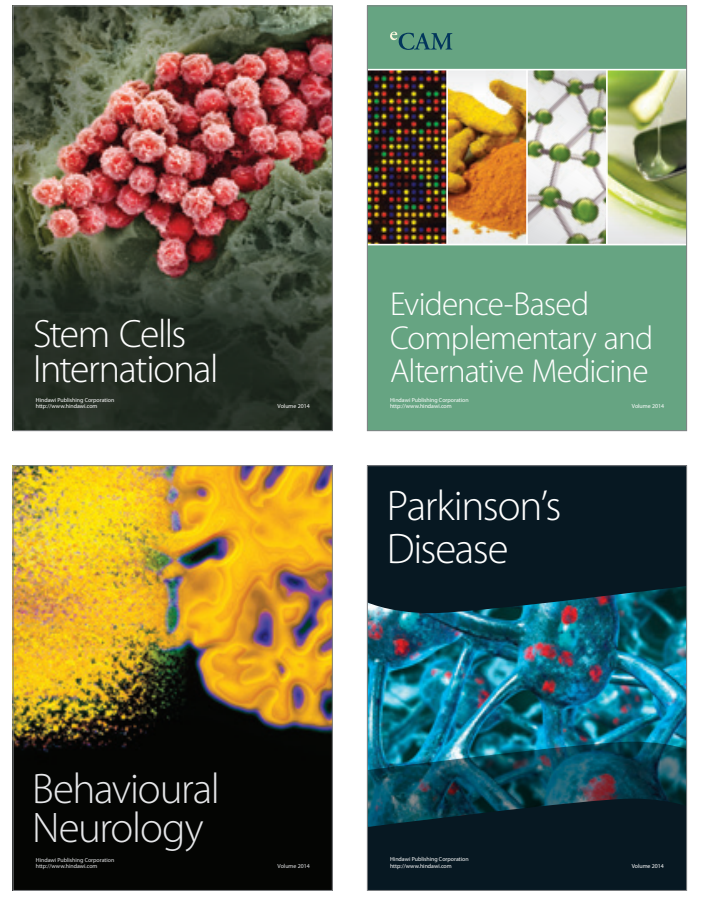
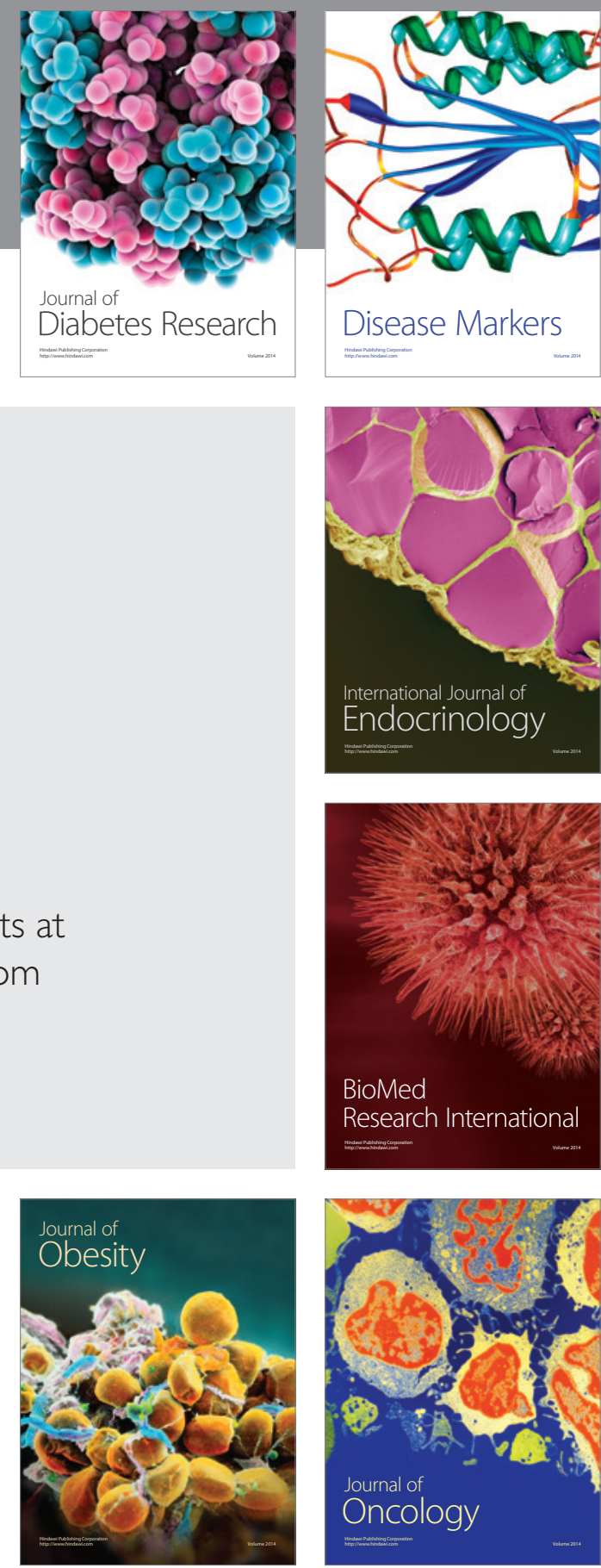

Disease Markers
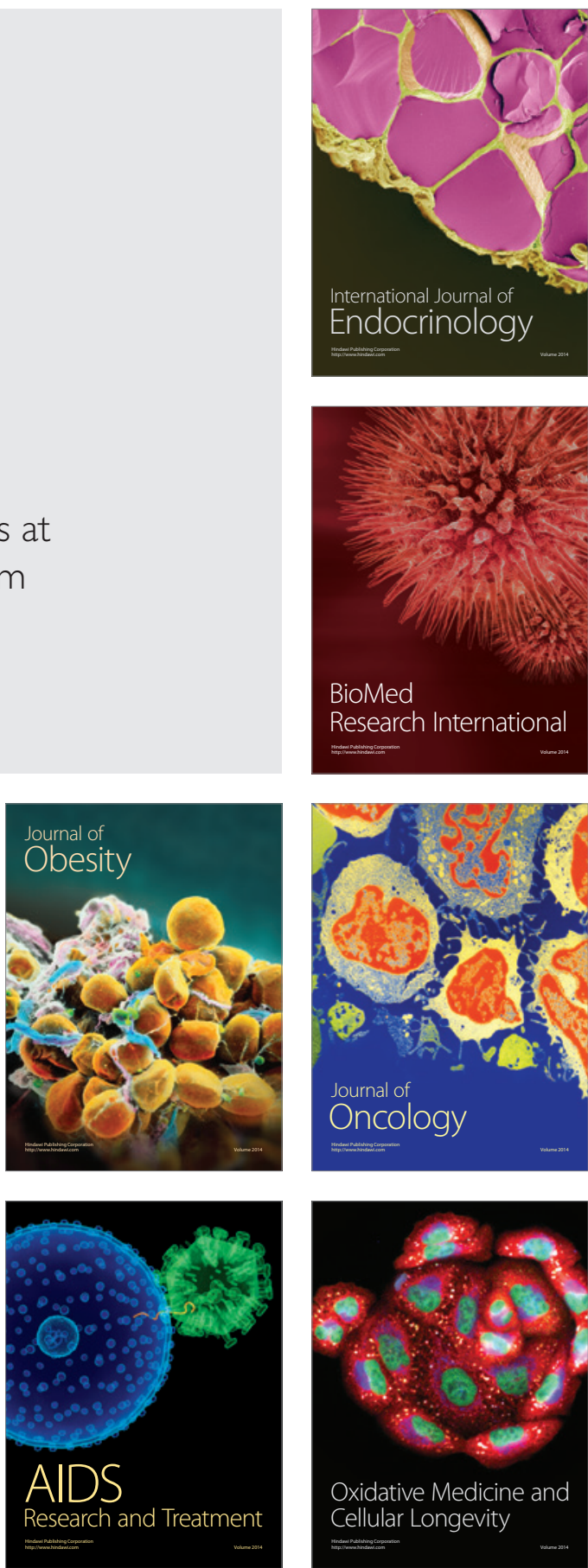